\title{
Isolation of Intact Elastin Fibers Devoid of Microfibrils
}

\author{
WILLEKE F. DAAMEN, M.Sc., THEO HAFMANS, B.Sc., JACQUES H. VEERKAMP, Ph.D., \\ and TOIN H. VAN KUPPEVELT, Ph.D.
}

\begin{abstract}
Purification protocols for elastin generally result in greatly damaged elastin fibers and this likely influences the biological response. We here describe a novel protocol for the isolation of elastin whereby the fibers stay intact, and introduce the term "elastin fiber" for intact elastic fibers with elastin as their sole component. As opposed to elastic fibers, elastin fibers do not contain any microfibrils or associated molecules. Elastin fibers were isolated from equine elastic ligaments according to various protocols and analyzed by sodium dodecyl sulfate polyacrylamide gel electrophoresis, amino acid quantification, immunofluorescence assay, transmission/scanning electron microscopy, and cellular reactivity in vivo. The optimal protocol comprised several extraction steps and trypsin digestion. Elastin fibers were free of contaminants and had a smooth, regular appearance. The cellular response to purified, intact elastin fibers was different in comparison with purified, but affected, fibers and to contaminated fibers. Intact fibers consisting only of elastin may be important for both fundamental and applied research, for example, tissue engineering, which need well-defined preparations to study the cellular biological effect of individual components.
\end{abstract}

\section{INTRODUCTION}

$\mathbf{E}$ LASTIC FIBERS are widely distributed over the body, especially in organs where elasticity is a major issue, like lung and blood vessels. ${ }^{1}$ Elastic fibers are composed of elastin and microfibrils. The latter is an intrinsic component of elastic fibers and is present on both the inside and the outside of elastic fibers. Microfibrils consist of and are associated with a variety of molecules including fibrillins, microfibril-associated (glyco)proteins, latent transforming growth factor $\beta$ binding proteins, fibulins, emilins, proteoglycans, and lysyl oxidase. ${ }^{2}$ Elastic fibers are crucial in tissue homeostasis, but are not readily replaced when damaged. ${ }^{3,4}$ This seriously hampers tissue regeneration, for example, in the case of skin injury, and could be due to difficulties in recapitulatingthe complex spatiotemporal expression patterns of proteins such as tropoelastin, lysyl oxidase, and fibrillins. ${ }^{5-7}$
Evidence exists that the biological behavior of cells toward proteins organized in fibrillar form differs from that toward single proteins, for example, collagen, where fibrillar and monomeric collagen give different responses. ${ }^{8}$ This possibly also holds for elastin. ${ }^{9,10}$ Elastin in fibrous form is not identical to its monomer, because of the formation of specific cross-links in (iso)desmosines. Cell biological studies of the effect of elastin in its native conformation, as a fiber, have been hampered by a lack of efficient isolation methodology. Current methods, such as treatment with $0.1 \mathrm{M} \mathrm{NaOH}$ at $95^{\circ} \mathrm{C}$ or autoclaving, are not able to adequately remove extracellular matrix components, such as collagen and microfibrillar components, and result in partial degradation of the elastic fiber. ${ }^{11,12}$ It is therefore impossible to study the cellular effect of elastin fibers per se.

We have previously presented a purification protocol for insoluble elastin. ${ }^{13}$ Although this protocol resulted in

Department of Biochemistry, NCMLS, Radboud University Medical Centre, Nijmegen, The Netherlands. 
a highly purified elastin preparation, additional experiments showed that this method was not adequate to obtain intact fibers. Therefore, we adapted several steps in this purification procedure to develop a novel method to obtain both highly purified and intact fibrillar elastin. We introduce the term "elastin fiber" to indicate an elastic fiber in which the only component is elastin and show that the biological response to elastin preparations depends on the integrity and purity of the fiber.

\section{MATERIALS AND METHODS}

\section{Elastin purification}

Equine ligamentum nuchae was used as a source of insoluble elastin. Elastic ligament was pulverized under liquid nitrogen conditions, using a Pulverisette 19 with a 1-mm sieve. Three purification procedures were compared (Fig. 1).

Procedure A. Procedure A is a traditional method based on treatment with $0.1 \mathrm{M} \mathrm{NaOH}$ at $95^{\circ} \mathrm{C}$ for 45 $\min .{ }^{11}$ This procedure makes use of three $24-\mathrm{h}$ extractions, each with $10 \mathrm{vol}(10 \mathrm{~mL} / \mathrm{g}$ wet weight tissue) of 1 $\mathrm{M} \mathrm{NaCl}$ at $4^{\circ} \mathrm{C}$. After each extraction step insoluble material was recovered by centrifugation at $13,000 \times g$, at $4^{\circ} \mathrm{C}$ for $20 \mathrm{~min}$. After the last extraction step, the pellet was washed with demineralized water, and defatted with $30 \mathrm{vol}$ of acetone (three times, $1 \mathrm{~h}$ each). The material was dried in a desiccator, subsequently suspended in 30 vol of $0.1 \mathrm{M} \mathrm{NaOH}$, and heated at $95^{\circ} \mathrm{C}$ for $45 \mathrm{~min}$. The

\begin{tabular}{|c|c|c|}
\hline & \multicolumn{2}{|c|}{ Procedure A } \\
\hline \multirow{13}{*}{$\begin{array}{c}\mathrm{NaCl} \text { extractions } \\
\downarrow \\
\text { acetone } \\
\text { extractions } \\
\downarrow \\
\mathrm{NaOH} \text { treatment }\end{array}$} & $\mathrm{NaCl}$ extractions & $\mathrm{NaCl}$ extractions \\
\hline & $\downarrow$ & \\
\hline & various & various \\
\hline & organic solvents & organic solvents \\
\hline & extractions & extractions \\
\hline & $\mathrm{CNBr}$ treatment & CNBr treatment \\
\hline & guanidine-HCl+ & $\underset{b}{\text { urea }+}$ \\
\hline & $\begin{array}{l}\text { 2-mercaptoethanol } \\
\text { extractions }\end{array}$ & $\begin{array}{l}\text { 2-mercaptoethanol } \\
\text { extractions }\end{array}$ \\
\hline & $\downarrow$ & t \\
\hline & $\begin{array}{l}\text { collagenase } \\
\text { digestion }\end{array}$ & trypsin digestion \\
\hline & $\downarrow$ & $\mathrm{NaCl}$ extractions \\
\hline & trypsin digestion & \\
\hline & $\mathrm{NaCl}$ extractions & \\
\hline
\end{tabular}

FIG. 1. Outline of the procedures used to isolate elastin from equine ligamentum nuchae. suspension was cooled, washed with demineralized water, and stored at $-80^{\circ} \mathrm{C}$.

Procedure B. Procedure B is adapted from Daamen et $a l .{ }^{13}$ and John and Thomas ${ }^{14}$ and results in a highly purified elastin preparation in which the fibers, however, are greatly affected. The procedure consists of different extraction steps and digestions with enzymes. Pulverized ligament was extracted three times overnight with $10 \mathrm{vol}$ of $1 \mathrm{M} \mathrm{NaCl}$ containing $0.02 \%$ (w/v) $\mathrm{NaN}_{3}$ at $4^{\circ} \mathrm{C}$. After each extraction step, insoluble material was recovered by centrifugation at $13,000 \times g$, at $4^{\circ} \mathrm{C}$ for $20 \mathrm{~min}$, washed with demineralized water, and resuspended in 10 vol of ethanol for $90 \mathrm{~min}$. The mixture was then filtered through a paper funnel and resuspended in $10 \mathrm{vol}$ of chloroform-methanol (2:1) for $90 \mathrm{~min}$. The mixture was filtered again through a paper funnel and resuspended in 10 vol of acetone for $30 \mathrm{~min}$, and the same procedure was repeated with 10 vol of ether. The insoluble material was dried in a desiccator. The dried powder was incubated in $15 \mathrm{vol}$ of $97 \%$ formic acid, and cyanogen bromide was added to a final concentration of $1 \%$ and left to react for $24 \mathrm{~h}$ under nonoxidizing conditions. The mixture was then diluted with $45 \mathrm{vol}$ of demineralized water, filtered, and washed with demineralized water until $\mathrm{pH} 6$ was reached. After washing, the pellet was extracted three times (24 h each) with $0.5 \mathrm{M}$ Tris- $\mathrm{HCl}$, containing $5 \mathrm{M}$ guanidium chloride, $1 \mathrm{M}$ 2-mercaptoethanol, and $0.02 \%$ $(\mathrm{w} / \mathrm{v}) \mathrm{NaN}_{3}(\mathrm{pH}$ 6.8). After the last extraction step the material was washed with demineralized water and incubated for $48 \mathrm{~h}$ at $37^{\circ} \mathrm{C}$ with $1000 \mathrm{U}$ of collagenase per gram of substrate in 10 vol of $0.2 \mathrm{M}$ Tris- $\mathrm{HCl}(\mathrm{pH} 7.4)$ containing $0.05 \mathrm{M} \mathrm{CaCl}_{2}$ and $0.02 \% \mathrm{NaN}_{3}$; after $24 \mathrm{~h}$ another $500 \mathrm{U}$ of collagenase per gram was added. The preparation was washed with demineralized water and between each washing step recovered by centrifugation at $13,000 \times g$ for $20 \mathrm{~min}$. After the last wash the pellet was resuspended in 10 vol of $0.1 \mathrm{M} \mathrm{NH}_{4} \mathrm{HCO}_{3}(\mathrm{pH} 8.2)$ containing $0.02 \%(\mathrm{w} / \mathrm{v}) \mathrm{NaN}_{3}$, and 10,000 $\mathrm{U}$ of trypsin for $4 \mathrm{~h}$ at $37^{\circ} \mathrm{C}$. The pellet was washed with demineralized water, followed by three overnight extractions with $10 \mathrm{vol}$ of $1 \mathrm{M} \mathrm{NaCl}$ containing $0.02 \%$ (w/v) $\mathrm{NaN}_{3}$, and washed again with demineralized water. The end product was stored at $-80^{\circ} \mathrm{C}$. Collagenase and trypsin were from Sigma (St. Louis, MO).

Procedure $C$. In the optimized procedure (procedure C; see Fig. 1), procedure B was adapted. A number of parameters was varied (see Results, below) including the nature of the chaotropic agent, the presence of $\mathrm{CNBr}$, the nature of the reducing agent, the presence of trypsin, and the presence, concentration, and duration of collagenase digestion. In the final procedure, $5 \mathrm{M}$ guanidine- $\mathrm{HCl}$ was replaced by $4 \mathrm{M}$ urea and the collagenase digestion was omitted. 
Sodium dodecyl sulfate polyacrylamide gel electrophoresis (SDS-PAGE)

Elastin preparations were incubated at $95^{\circ} \mathrm{C}$ for $10 \mathrm{~min}$ under reducing conditions $(5 \%[\mathrm{v} / \mathrm{v}] 2$-mercaptoethanol) and analyzed on a $10 \%(\mathrm{w} / \mathrm{v})$ polyacrylamide gel. This method is particularly useful for analyzing purity because contaminants and elastin degradation products, but not fibrillar elastin, will penetrate the gel. Proteins were visualized by silver staining, using a $0.1 \%(\mathrm{w} / \mathrm{v}) \mathrm{AgNO}_{3}$ solution.

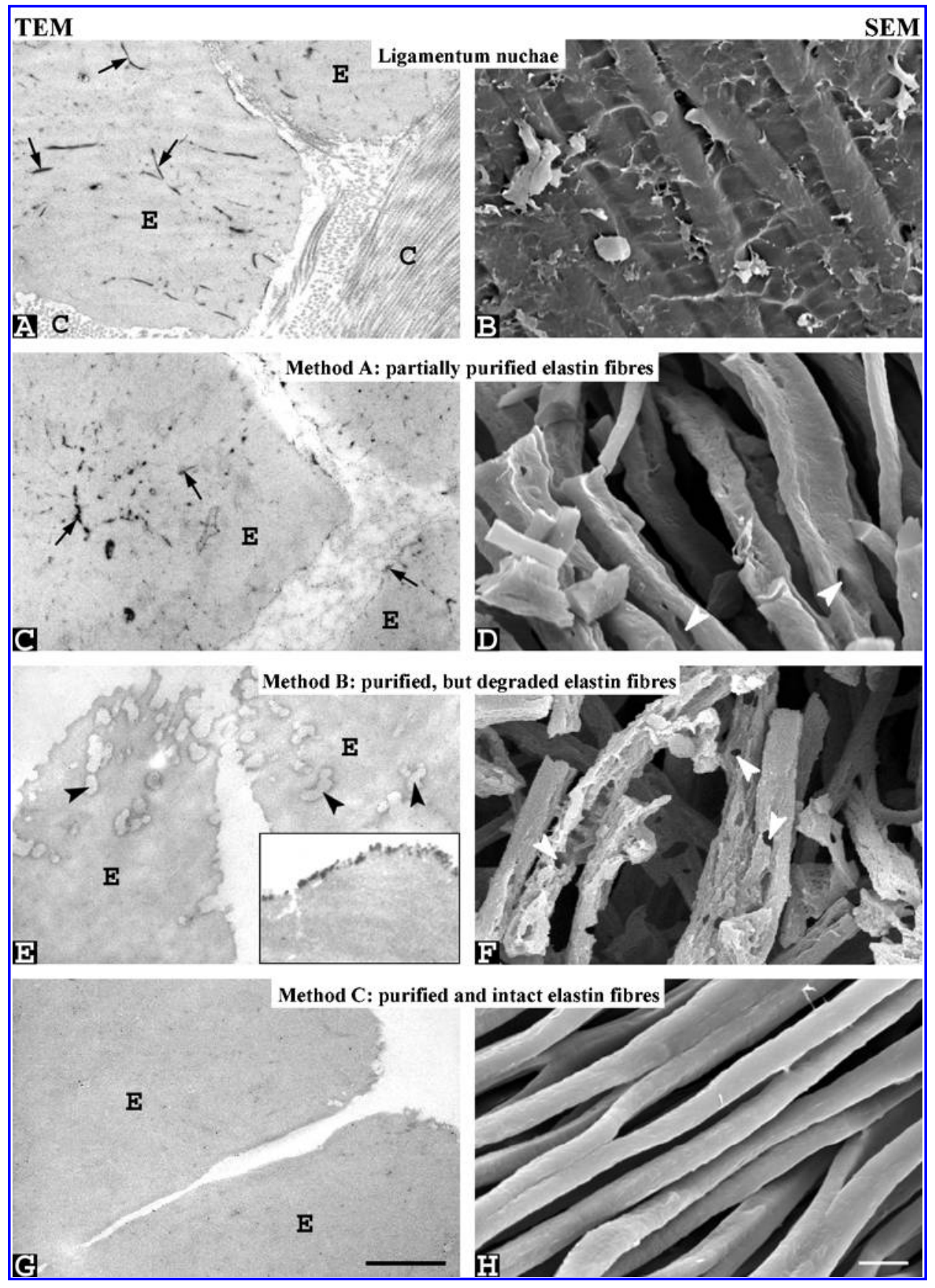

FIG. 2. Transmission (A, C, E, and $\mathbf{G})$ and scanning electron micrographs (B, D, F, and $\mathbf{H})$ of equine ligamentum nuchae (A, and $\mathbf{B}$ ) and of elastin purified according to procedure A $(\mathbf{C}$, and $\mathbf{D})$, procedure $\mathrm{B}(\mathbf{E}$, and $\mathbf{F})$, and procedure $\mathrm{C}(\mathbf{G}$, and $\mathbf{H})$. Insert in $(\mathbf{E})$ shows $\mathrm{SiO}_{2}$ attached to an elastin fiber. Note the disruption of fibers when using procedures $\mathrm{A}$ and $\mathrm{B}$, and the smooth, regular appearance of fibers when using procedure C. $E$, elastin; $C$, collagen fibrils; arrows indicate microfibrillar remnants; arrowheads indicate holes in the fibers. Scale bars: $1 \mu \mathrm{m}$ in TEM micrographs and $10 \mu \mathrm{m}$ in SEM micrographs. 


\section{Amino acid analysis}

Elastin samples were hydrolyzed under vacuum over $\mathrm{NaOH}$ pellets with $6 \mathrm{M} \mathrm{HCl}$ for $22 \mathrm{~h}$ at $110^{\circ} \mathrm{C}$, dried under vacuum, and dissolved in $10 \mathrm{mM} \mathrm{HCl}$. Hydrolyzed samples were first deproteinized by addition of an $18.8 \%(w / v) 5$-sulfosalicylic acid solution (Fluka Chemie, Buchs, Switzerland), containing norleucine (Sigma) as an internal standard. Separation of amino acids was obtained by ion-exchange column chromatography on a Biochrom 20 amino acid analyzer (Amersham Biosciences/GE Healthcare, Piscataway, $\mathrm{NJ}$ ), using lithium buffers of increasing $\mathrm{pH}$.

\section{Immunohistochemistry}

Immunofluorescence microscopy was used to study the presence of elastin, type I collagen, and fibrillin in the elastin preparations. Elastin preparations were suspended in demineralized water and frozen in liquid nitrogen. Ligamentum nuchae was frozen directly in liquid nitrogen. Cryosections of frozen preparations were mounted onto glass slides. After blocking with $1 \%(\mathrm{w} / \mathrm{v})$ bovine serum albumin (BSA) in phosphate-buffered saline (PBS), sections were incubated with mouse anti-bovine elastin $\mathrm{IgG}$ (diluted 1:1000; Sigma), rabbit anti-bovine type I collagen IgG (diluted 1:100, Chemicon International, Temecula, CA), and mouse anti-bovine fibrillin IgG (diluted
1:50; Chemicon International) for $90 \mathrm{~min}$ and washed with PBS, followed by a 1-h incubation with Alexa labeled secondary antibodies (diluted 1:100; Molecular Probes, Eugene, OR). All antibodies were diluted in PBS containing $1 \%(\mathrm{w} / \mathrm{v})$ BSA. Sections were washed and mounted in Mowiol.

\section{Transmission electron microscopy (TEM)}

Elastin preparations were embedded in $1.5 \%(\mathrm{w} / \mathrm{v})$ agarose, fixed in $2 \%(\mathrm{v} / \mathrm{v})$ glutaraldehyde in $0.1 \mathrm{M}$ phosphate buffer ( $\mathrm{pH} 7.4$ ), postfixed with $1 \%$ (w/v) osmium tetroxide, dehydrated in an ascending series of ethanols, and embedded in Epon 812. Ultrathin sections $(60 \mathrm{~nm})$ were picked up on Formvar-coated grids, poststained with lead citrate and uranyl acetate, and examined in a 1010 electron microscope (JEOL, Tokyo, Japan).

\section{Scanning electron microscopy}

Scanning electron microscopy (SEM) was used to study the intactness of the elastin fibers. Lyophilized elastin preparations were mounted on stubs and sputtered with an ultrathin layer of gold in a Polaron E5100 SEM coating system (Quorum Technologies, Newhaven, UK). Specimens were studied with a JEOL JSM-6310 SEM apparatus operating at $15 \mathrm{kV}$.

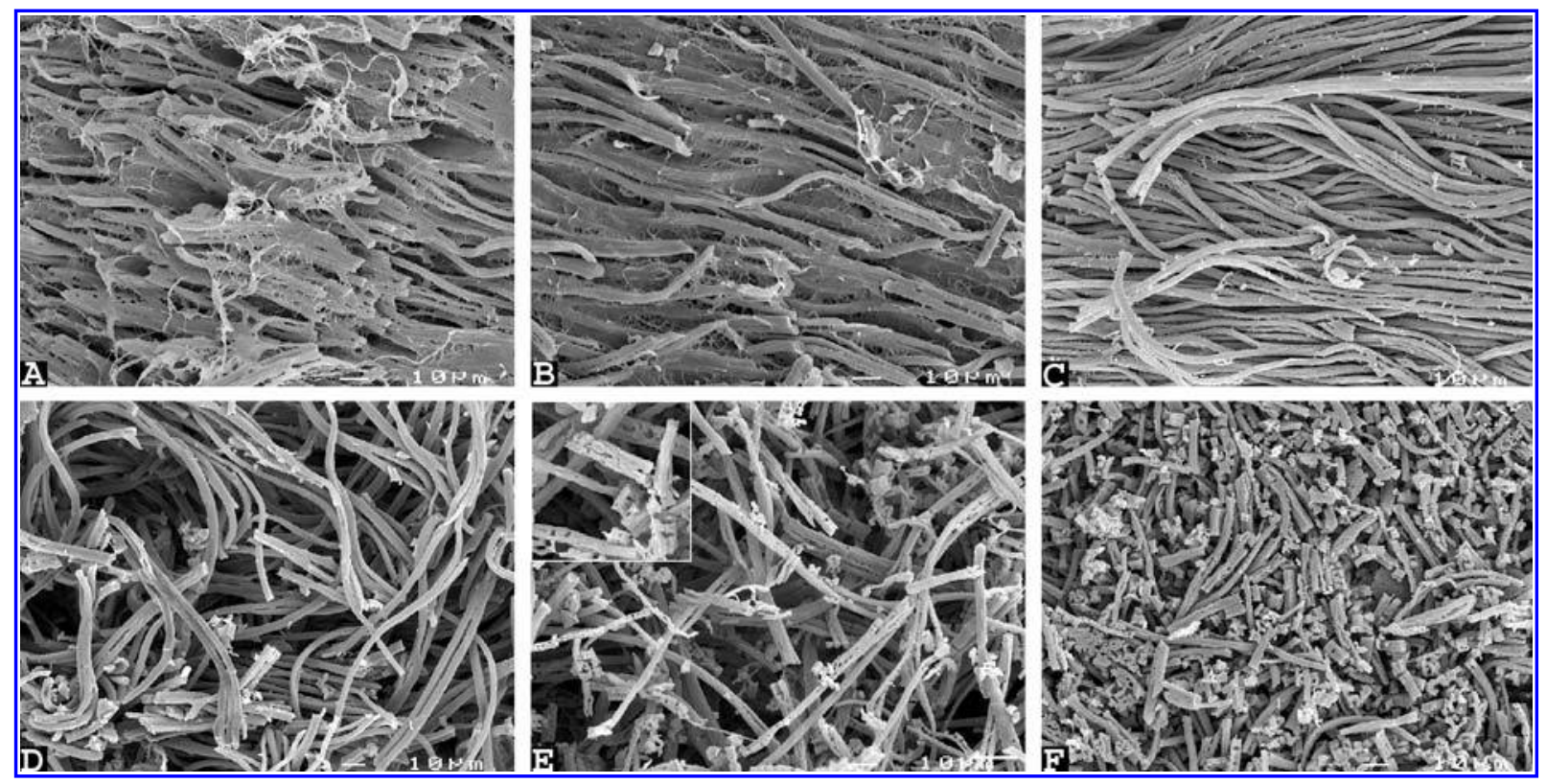

FIG. 3. Scanning electron micrographs of partly purified elastin after each purification step of method B (see Fig. 1 for sequential steps): (A) after $\mathrm{NaCl}$ extraction, (B) after extraction with organic solvents, (C) after $\mathrm{CNBr}$ in formic acid step, (D) after guanidium chloride/2-mercaptoethanol extractions, (E) after collagenase digestions, (F) after trypsin digestion. For example, elastin in $(\mathbf{C})$ was isolated by $\mathrm{NaCl}$ extraction, organic solvent steps, and guanidium chloride/2-mercaptoethanol extractions. (E) shows an enlargement of affected fibers. Note that elastin fibers are damaged after collagenase digestion. Scale bars: $10 \mu \mathrm{m}$. 


\section{Subcutaneous implantation}

National Institutes of Health (NIH, Bethesda, MD) guidelines for the care and use of laboratory animals (NIH publication 85-23 Rev. 1985) were observed. The study was approved by the Ethics Committee of the University of Nijmegen (Nijmegen, The Netherlands). SpragueDawley rats (male, 21 days old) were purchased from Harlan (Zeist, The Netherlands). The animals were fed a pelleted diet (RMH-B, 10 mm; Hope Farms, Woerden, The Netherlands) and water ad libitum. Scaffolds composed of $50 \%$ purified collagen fibrils ${ }^{15}$ and $50 \%$ elastin fibers (isolated according to procedures A, B, and C) were washed in $70 \%(\mathrm{v} / \mathrm{v})$ ethanol (four times, $30 \mathrm{~min}$ each) and in sterile phosphate-buffered saline ( $\mathrm{pH}$ 7.2) (eight times, $30 \mathrm{~min}$ each) at $22^{\circ} \mathrm{C}$. Rats were anesthetized with isoflurane. After disinfection, subcutaneous pockets were made to the right and left of two midline incisions on the back. Punches (diameter, $6 \mathrm{~mm}$; thickness, $6 \mathrm{~mm}$ ) of the scaffolds were implanted in the pockets at a distance of about $1 \mathrm{~cm}$ from the incisions (four implants per rat). For each scaffold two rats received two punches of the same scaffold. Implants with surrounding tissue were harvested after 3 days, fixed in $4 \%(\mathrm{v} / \mathrm{v})$ formaldehyde in phosphate buffer ( $\mathrm{pH} 7.2)$ for $24 \mathrm{~h}$ at $4^{\circ} \mathrm{C}$, and embedded in paraffin. Sections of $5 \mu \mathrm{m}$ were mounted onto glass slides, dewaxed in xylol, hydrated through a graded series of ethanol, and hematoxylin-eosin stained. ${ }^{16}$

\section{RESULTS AND DISCUSSION}

The general strategy in isolating elastin is to remove/degrade all other biomolecules. Initially the tissue is rinsed with $\mathrm{NaCl}$-containing solutions to remove saltsoluble proteins, and with organic solvents to remove lipid-containing molecules. Traditional methods (as exemplified by method A; Fig. 1) then solubilize remaining proteins by partial hydrolysis, using harsh methods such as $\mathrm{NaOH}$ treatment at high temperature. Elastin is largely resistant to these treatments. Alternative methods (as exemplified by method B; Fig. 1) rely on further washings with chaotropic salts (guanidine- $\mathrm{HCl}$ ), and cleavage of proteins by $\mathrm{CNBr}$ treatment (cleaves at the site of methionine residues present in virtually all proteins, but not elastin) and/or proteases (e.g., collagenase and trypsin). The methods used so far, however, result in either contaminated and/or disrupted elastin fibers. In this study we developed a novel isolation protocol, based on method B (Fig. 1), which resulted in purified and intact elastin fibers. A number of different analytical techniques including sodium dodecyl sulfate-polyacrylamide gel electrophoresis (SDS-PAGE), amino acid analysis, immunofluorescence microscopy, and transmission and scanning electron microscopy were used to study purity and intactness. The advantages and disadvantages of each of these techniques have been discussed. ${ }^{13}$

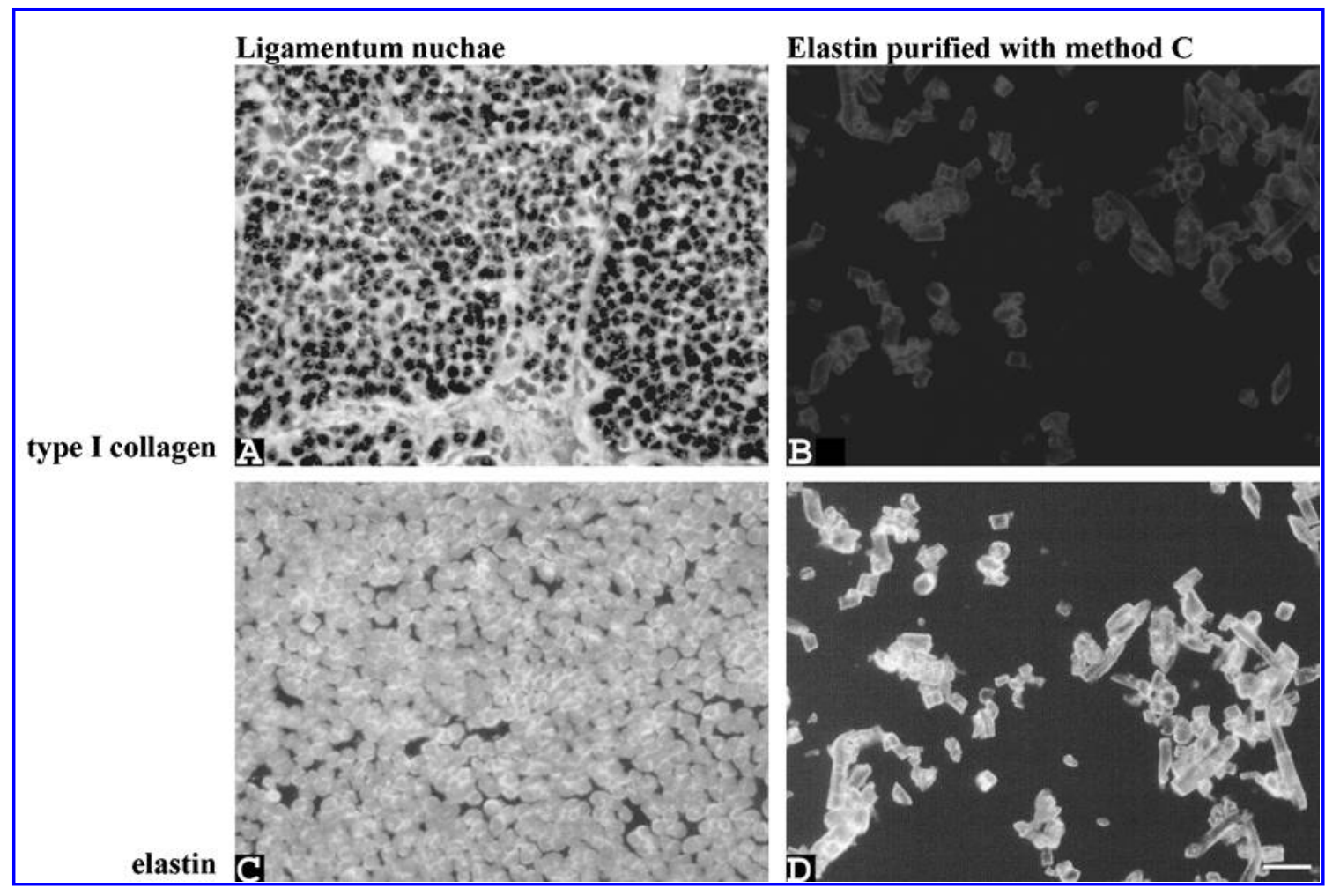

FIG. 4. Immunostaining for type I collagen (A and $\mathbf{B})$ and elastin $(\mathbf{C}$ and $\mathbf{D})$ in ligamentum nuchae $(\mathbf{A}$ and $\mathbf{C})$ and elastin purified according to method $\mathbf{C}$ (B and $\mathbf{D})$. Scale bar: $20 \mu \mathrm{m}$. 
In ligamentum nuchae (the source of elastin fibers), elastic fibers are surrounded by collagen fibrils and other (extra)cellular components, and contain microfibrils at the periphery and within the fibers. The elastic fibers are present as bundles and are connected by collagen (Fig. $2 \mathrm{~A}$ and $\mathrm{B}$ ). EM showed that elastic fibers purified by conventional procedures, such as procedure $\mathrm{A}$, still contained microfibrillar remnants and that they were partially damaged (Fig. 2C and D). SDS-PAGE of elastin purified by method A gave a smear of high molecular mass impurities on a silver-stained gel (elastin fibers are too large to enter the gel), whereas method B resulted in an empty lane (results not shown). Method B resulted in highly purified elastin, but the intactness of the fibers was severely comprised as indicated by EM analysis (Fig. 2E and F). We therefore adapted this method to obtain purified as well as intact elastin fibrils.

A number of parameters was varied. Omission of the $\mathrm{CNBr}$ step resulted in damaged as well as impure fibers. Replacement of 2-mercaptoethanol with dithiothreitol (DTT) did result in pure elastin, but the fibers were damaged. Omission of both the collagenase and trypsin enzyme digestions led to intact, but impure, fibers. Omission only of trypsin resulted in pure, but damaged, fibrils. SEM analysis of elastic fibers after various extraction steps indeed indicated that the collagenase treatment led to destruction of the fibers (Fig. 3, compare Fig. 3D with Fig. 3E). The collagenase preparation used may contain other proteases (according to the manufacturer's data sheet), possibly elastase. Reduction of the amount of collagenase and/or time of digestion, however, still resulted in damaged fibers. We therefore omitted the collagenase treatment. To evaluate whether collagen was still removed, immunofluorescence and TEM were applied. No collagen fibrils and no immunoreactivity with anti-collagen antibodies were detected (Fig. 4 and Fig. 2G). Elastin purified according to method $\mathrm{C}$ did not show immunoreactivity with anti-fibrillin antibodies (results not shown). Immunostaining for elastin, however, was highly positive. Collagen fibrils were largely removed by chaotropic salt/mercaptoethanol/CNBr treatments. Trypsin was necessary for the removal of remnants of microfibrillar components, and although, in principle, trypsin is able to digest elastin (it cleaves near lysine and arginine residues, which are present in elastin), results showed that with a 4-h digestion the elastin fibers remained intact (Fig. 2H). Using transmission electron microscopy (TEM), it was noticed that an electron-dense precipitate was present (see inset, Fig. 2E). This could be attributed to the guanidine- $\mathrm{HCl}$ step. Guanidine- $\mathrm{HCl}$ sometimes contains an anticaking agent $\left(\mathrm{SiO}_{2}\right)$ that sticks to elastin fibers and can not be removed. Omission of guanidine- $\mathrm{HCl}$, however, did not result in a pure elastin preparation and therefore it was replaced by urea, another chaotropic agent, which gave satisfactory results. Taken together, the omission of collagenase and the replacement of guanidine- $\mathrm{HCl}$ by urea (procedure $\mathrm{C}$ ) resulted in highly purified, intact elastin fibers (Fig. 2G and H). SDS-PAGE, immunofluorescence, and transmission electron microscopy gave similar results for elastin isolated by methods $\mathrm{B}$ and $\mathrm{C}$, indicating that method $\mathrm{C}$ results in highly purified elastin. However, amino acid analysis of elastin purified by methods B and C gave slightly different findings (Table 1). For elastin purified according to method $\mathrm{C}$, frequently occurring amino acid residues such as glycine, proline, and valine appeared at levels resembling the theoretical amino acid composition of bovine elastin more closely than elastin isolated by method B (equine cDNA was not available). Because method $\mathrm{C}$ also resulted in intact elastin fibers, this may indicate that these elastin molecules are less prone to proteolysis compared with method B elastin. This may be crucial for correct cell adhesion, for instance, mediated by integrin $\alpha_{\mathrm{v}} \beta_{3}$ which binds to the C-terminal end of

Table 1. Amino Acid Composition of Elastin Purified by Methods B and $\mathrm{C}^{\mathrm{a}}$

\begin{tabular}{lccc}
\hline & Theory $^{\mathrm{b}}$ & Method $B$ & Method C \\
\hline Ala & 211 & $221 \pm 9$ & $241 \pm 10$ \\
Arg & 7 & $6 \pm 1$ & $8 \pm 2$ \\
Asx & 4 & $5 \pm 0$ & $4 \pm 1$ \\
Cys & 3 & $3 \pm 0$ & $3 \pm 0$ \\
Glx & 14 & $19 \pm 1$ & $22 \pm 2$ \\
Gly & 319 & $235 \pm 11$ & $289 \pm 14$ \\
His & 0 & $0 \pm 0$ & $0 \pm 0$ \\
Hyl & & $0 \pm 0$ & $0 \pm 0$ \\
Hyp & & $7 \pm 2$ & $6 \pm 1$ \\
Ile & 25 & $20 \pm 1$ & $22 \pm 8$ \\
Leu & 60 & $72 \pm 3$ & $51 \pm 12$ \\
Lys & 53 & $7 \pm 1$ & $5 \pm 2$ \\
Met & & $0 \pm 0$ & $0 \pm 0$ \\
Phe & 29 & $35 \pm 2$ & $34 \pm 5$ \\
Pro & 119 & $147 \pm 4$ & $129 \pm 4$ \\
Ser & 10 & $8 \pm 1$ & $7 \pm 3$ \\
Thr & 11 & $15 \pm 1$ & $16 \pm 2$ \\
Trp & 0 & $0 \pm 0$ & $0 \pm 0$ \\
Tyr & 10 & $25 \pm 1$ & $12 \pm 4$ \\
Val & 126 & $174 \pm 6$ & $150 \pm 12$ \\
Des & & $0.5 \pm 0.0$ & $0.6 \pm 0.1$ \\
Ide & & $0.5 \pm 0.0$ & $0.5 \pm 0.0$ \\
\hline
\end{tabular}

aValues represent means \pm standard deviation $(n=3)$, expressed per 1000 amino acid residues and are not corrected for losses during hydrolysis. Des, desmosine; Ide, isodesmosine. Amino acid composition of elastin purified according to method B are from method 3c. ${ }^{13}$

${ }^{\mathrm{b}}$ The amino acid composition of bovine elastin was theoretically calculated from the cDNA of tropoelastin. Posttranslational modifications and alternative splicings are therefore not taken into account. ${ }^{24,25}$ 


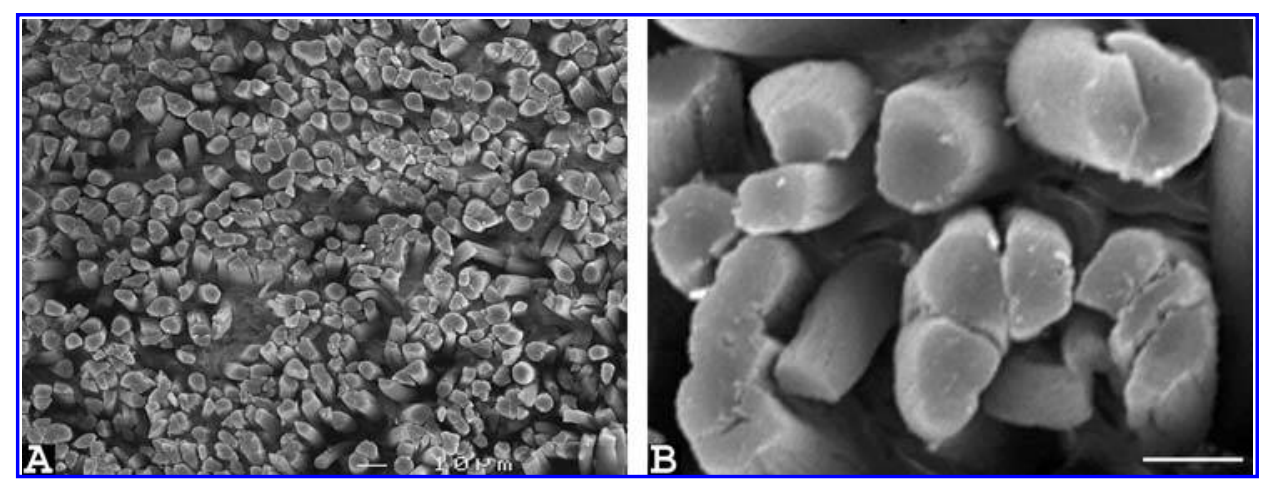

FIG. 5. Scanning electron micrographs of cross-sectioned elastin fibers purified according to procedure C. Elastin is distributed throughout the whole fiber, and no holes are present. Scael bars: (A) $10 \mu \mathrm{m}$; (B) $5 \mu \mathrm{m}$.

elastin. ${ }^{17}$ Figure 5 shows that elastin was present homogeneously in elastin fibers purified according to method C. Yields for the different purification procedures (A, B, and C) were similar and were, on a dry weight basis, 21, 20 , and $22 \%$ respectively, of the original ligament.

The cellular response toward elastin preparations made by procedure A, B, or $\mathrm{C}$ was clearly different (Fig. 6). On implantation of impure, partially affected elastin (procedure A), many cells (including macrophages, fibroblasts, and neutrophils) infiltrated the scaffold. Implantation of pure, but severely affected, elastin (procedure B) gave rise to the influx of large amounts of neutrophils. However, pure and intact fibers (procedure C) resulted in only a mild cellular response with few cells infiltrating the scaffold. Differences in the purity of insoluble elastin preparations thus gave a distinct cellular response on implantation. Moreover, these results indicated that the intactness of elastin fibers exerts a major influence on cellular response. It has been demonstrated that elastin degradation is accompanied by an inflammatory response, for example, in animal models of elastase-induced emphysema ${ }^{18}$ and elastase-induced abdominal aortic aneurysms. ${ }^{19,20}$ Therefore, degraded elastin fibers (as obtained by method B) likely induce an inflammatory response. Also, partly purified elastin (as in method A) contains (degradation products of) microfibrillar components that may attract neutrophils. Similarly, an impure preparation of collagen-elastin (a mildly cleansed membrane of porcine origin composed mainly of collagen [70\%] and elastin) resulted in inflammation, activation of macrophages, and angiogenesis. ${ }^{21}$

The availability of isolated elastin in its native, fibrillar conformation may be important for both fundamental and applied research. For cell biological studies of elastin it is now possible to study the effect of mature extracellular elastin in fibrous form, without introducing artifacts

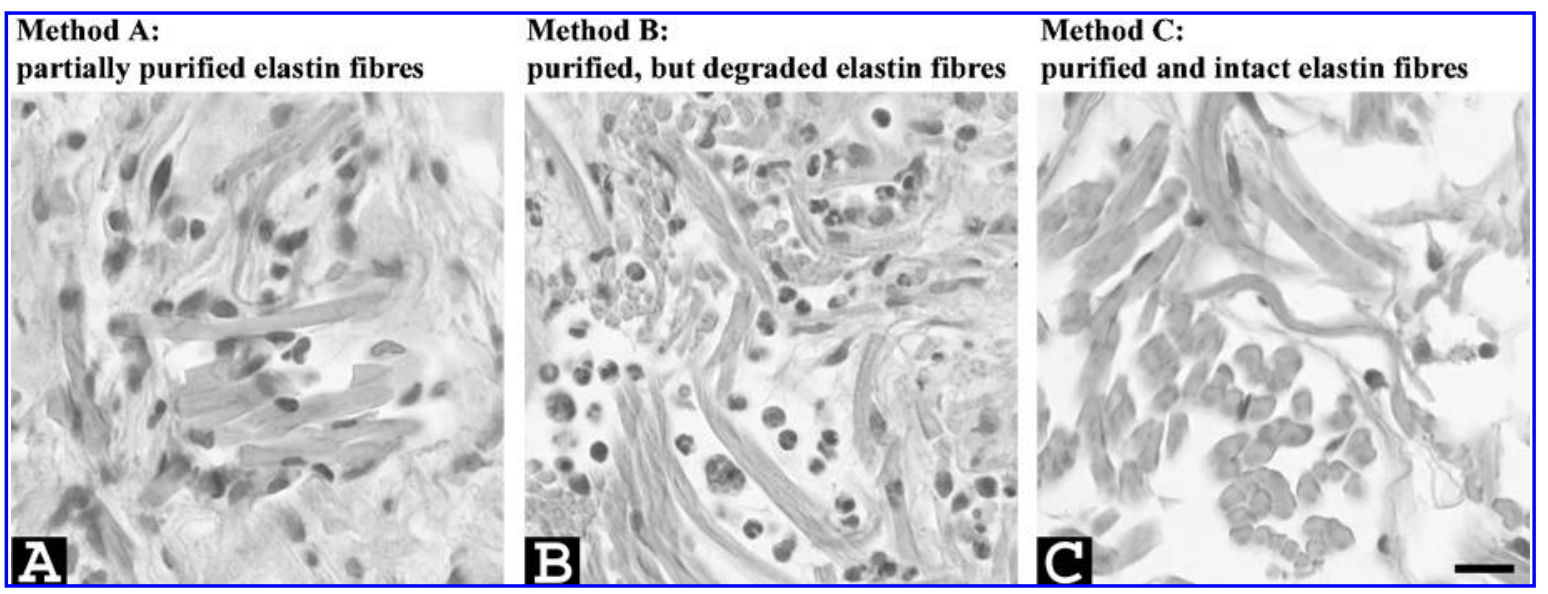

FIG. 6. Light microscopy overview of the cellular response to scaffolds 3 days after subcutaneous implantation in SpragueDawley rats. Scaffolds composed of elastin and collagen (1:1) were used. (A-C) elastin prepared according to procedure A, B, and $\mathrm{C}$, respectively. Note that few cells were found on implantation of pure intact elastin fibers (procedure C), whereas many cells were present when using other elastin preparations. Sections were stained with H\&E. Scale bar: $10 \mu \mathrm{m}$. 
to the system caused by affected fibers and/or impurities. It is also possible to test whether conflicting data, for example, concerning to the specificity of matrix metalloproteinases, ${ }^{22}$ are due to impurities still present within or associated with the elastic fiber. In applied research, for example, concerning the use of elastin in biomaterials and tissue engineering, purified intact fibers may be useful when preparing defined bioscaffolds from scratch, ${ }^{23}$ thus avoiding unwanted immunological reactions to contaminations, and allowing studies of the body's response to a single component, elastin.

In summary, we have developed a purification method that results in highly purified, intact fibers of elastin. We called these fibers "elastin fibers" as opposed to elastic fibers.

\section{ACKNOWLEDGMENTS}

This study was financially supported by the Dutch Ministry of Economic Affairs (grant IIE 98012). The authors thank Rien van der Gaag (Central Instruments Facility, Faculty of Sciences, Radboud University Nijmegen), and Marloes Bruckwilder and Ingrid Beckmann-Bumer (Department of Pediatrics) for performing amino acid analyses, and Gerwin Schaafsma for technical assistance.

\section{REFERENCES}

1. Debelle, L., and Tamburro, A.M. Elastin: Molecular description and function. Int. J. Biochem. Cell Biol. 31, 261, 1999.

2. Kielty, C.M., Sherratt, M.J., and Shuttleworth, C.A. Elastic fibers. J. Cell Sci. 115, 2817, 2002.

3. Berthod, F., Germain, L., Li, H., Xu, W., Damour, O., and Auger, F.A. Collagen fibril network and elastic system remodeling in a reconstructed skin transplanted on nude mice. Matrix Biol. 20, 463, 2001.

4. Kadoya, K., Amano, S., Inomata, S., Tsunenaga, M., Matsuzaki, K., Oshima, H., Tanabe, M., Kumagai, N., and Nishiyama, T. Evaluation of autologous cultured epithelium as replacement skin after tattoo excision: Correlation between skin texture and histological features. Br. J. Dermatol. 149, 377, 2003.

5. Bujan, J., Gimeno, M.J., Jimenez, J.A., Kielty, C.M., Mecham, R.P., and Bellon, J.M. Expression of elastic components in healthy and varicose veins. World J. Surg. 27, 901, 2003.

6. Visconti, R.P., Barth, J.L., Keeley, F.W., and Little, C.D. Codistribution analysis of elastin and related fibrillar proteins in early vertebrate development. Matrix Biol. 22, 109, 2003.

7. Liu, X., Zhao, Y., Gao, J., Pawlyk, B., Starcher, B., Spencer, J.A., Yanagisawa, H., Zuo, J., and Li, T. Elastic fiber homeostasis requires lysyl oxidase-like 1 protein. Nat. Genet. 36, 178, 2004.
8. Ichii, T., Koyama, H., Tanaka, S., Kim, S., Shioi, A., Okuno, Y., Raines, E.W., Iwao, H., Otani, S., and Nishizawa, Y. Fibrillar collagen specifically regulates human vascular smooth muscle cell genes involved in cellular responses and the pericellular matrix environment. Circ. Res. 88, 460, 2001.

9. Tobias, J.W., Bern, M.M., Netland, P.A., and Zetter, B.R. Monocyte adhesion to subendothelial components. Blood 69, 1265, 1987.

10. Svitkina, T.M., and Parsons, D.F. Binding of some metastatic tumor cell lines to fibrous elastin and elastin peptides. Int. J. Cancer 53, 824, 1993.

11. Lansing, A.I., Rosenthal, T.B., Alex, M., and Dempsey, W. The structure and chemical characterization of elastic fibers as revealed by elastase and by electron microscopy. Anat. Rec. 114, 555, 1952.

12. Rasmussen, B.L., Bruenger, E., and Sandberg, L.B. A new method for purification of mature elastin. Anal. Biochem. 64, 255, 1975.

13. Daamen, W.F., Hafmans, T., Veerkamp, J.H., and Van Kuppevelt, T.H. Comparison of five procedures. for the purification of insoluble elastin. Biomaterials 22, 1997, 2001.

14. John, R., and Thomas, J. Chemical compositions of elastins isolated from aortas and pulmonary tissues of humans of different ages. Biochem. J. 127, 261, 1972.

15. Pieper, J.S., Oosterhof, A., Dijkstra, P.J., Veerkamp, J.H., and Van Kuppevelt, T.H. Preparation and characterization of porous crosslinked collagenous matrices containing bioavailable chondroitin sulphate. Biomaterials 20, 847, 1999.

16. Bancroft, J.D., and Stevens, A. Theory and Practice of Histological Techniques. Edinburgh: Churchill Livingstone, 1990.

17. Rodgers, U.R., and Weiss, A.S. Integrin $\alpha_{\mathrm{v}} \beta_{3}$ binds a unique non-RGD site near the C-terminus of human tropoelastin. Biochimie 86, 173, 2004.

18. Snider, G.L., Lucey, E.C., and Stone, P.J. Animal models of emphysema. Am. Rev. Respir. Dis. 133, 149, 1986.

19. Anidjar, S., Salzmann, J.L., Gentric, D., Lagneau, P., Camilleri, J.P., and Michel, J.B. Elastase-induced experimental aneurysms in rats. Circulation 82, 973, 1990.

20. Halpern, V.J., Nackman, G.B., Gandhi, R.H., Irizarry, E., Scholes, J.V., Ramey, W.G., and Tilson, M.D. The elastase infusion model of experimental aortic aneurysms: Synchrony of induction of endogenous proteinases with matrix destruction and inflammatory cell response. J. Vasc. Surg. 20, 51, 1994.

21. Klein, B., Schiffer, R., Hafemann, B., Klosterhalfen, B., and Zwadlo-Klarwasser, G. Inflammatory response to a porcine membrane composed of fibrous collagen and elastin as dermal substitute. J. Mater. Sci. Mater. Med. 12, 419, 2001.

22. Aoki, Y., and Yamazaki-Hase, T. Both medullasin and human leukocyte elastase are essentially devoid of elastinolytic activity. J. Biochem. (Tokyo) 114, 122, 1993.

23. Daamen, W.F., Van Moerkerk, H.Th.B., Hafmans, T., Buttafoco, L., Poot, A.A., Veerkamp, J.H., and Van Kuppevelt, T.H. Preparation and evaluation of molecularly-de- 
fined collagen-elastin-glycosaminoglycan scaffolds for tissue engineering. Biomaterials 24, 4001, 2003.

24. Yeh, H., Ornstein-Goldstein, N., Indik, Z., Sheppard, P., Anderson, N., Rosenbloom, J.C., Cicila, G., and Yoon, K. Sequence variation of bovine elastin mRNA due to alternative splicing. Collagen Relat. Res. 7, 235, 1987.

25. Raju, K., and Anwar, R.A. Primary structures. of bovine elastin $\mathrm{a}, \mathrm{b}$, and $\mathrm{c}$ deduced from the sequences of cDNA clones. J. Biol. Chem. 262, 5755, 1987.
Address reprint requests to: Toin H. van Kuppevelt, Ph.D. Department of Biochemistry, 194 NCMLS

Radboud University Nijmegen Medical Centre P.O. Box 9101 6500 HB Nijmegen, The Netherlands E-mail: a.vankuppevelt@ncmls.ru.nl 


\section{This article has been cited by:}

1. Sarit-Sara Sivan, Benno Van El, Yulia Merkher, Christian E.H. Schmelzer, Anne-Marie Zuurmond, Andrea Heinz, Ellen Wachtel, Peter-Paul Varga, Aron Lazary, Marco Brayda-Bruno, Alice Maroudas. 2012. Longevity of Elastin in Human Intervertebral Disc as Probed by the Racemization of Aspartic Acid. Biochimica et Biophysica Acta (BBA) - General Subjects . [CrossRef]

2. Willeke Daamen, Kaeuis Faraj, Martin Koens, Gerwen Lammers, Katrien Brouwer, Peter Uijtdewilligen, Suzan Nillesen, Luc Roelofs, Jody Nuininga, Paul Geutjes, Wouter Feitz, Toin van KuppeveltExtracellular Matrix-Based Scaffolds from Scratch 385-398. [CrossRef]

3. Martin J.W. Koens, Paul J. Geutjes, Kaeuis A. Faraj, Jöns Hilborn, Willeke F. Daamen , Toin H. van Kuppevelt . 2011. Organ-Specific Tubular and Collagen-Based Composite Scaffolds. Tissue Engineering Part C: Methods 17:3, 327-335. [Abstract] [Full Text HTML] [Full Text PDF] [Full Text PDF with Links]

4. Willeke F. Daamen, Suzan T.M. Nillesen, Ronnie G. Wismans, Dieter P. Reinhardt, Theo Hafmans , Jacques H. Veerkamp, Toin H. van Kuppevelt A Biomaterial Composed of Collagen and Solubilized Elastin Enhances Angiogenesis and Elastic Fiber Formation Without Calcification 185-194. [Abstract] [Full Text PDF] [Full Text PDF with Links]

5. G. Lammers, G.S. Tjabringa, J. Schalkwijk, W.F. Daamen, T.H. van Kuppevelt. 2009. A molecularly defined array based on native fibrillar collagen for the assessment of skin tissue engineering biomaterials. Biomaterials 30:31, 6213-6220. [CrossRef]

6. Yolanda Garcia , Naik Hemantkumar, Russell Collighan, Martin Griffin, Jose Carlos Rodriguez-Cabello, Abhay Pandit . 2009. In Vitro Characterization of a Collagen Scaffold Enzymatically Cross-Linked with a Tailored Elastin-like Polymer. Tissue Engineering Part A 15:4, 887-899. [Abstract] [Full Text HTML] [Full Text PDF] [Full Text PDF with Links]

7. W.F. Daamen, D. Löwik, T.H. van Kuppevelt. 2008. Nicked elastin fibres do not calcify after subcutaneous implantation. Journal of Controlled Release 132:3, e23-e24. [CrossRef]

8. Robert P. Mecham. 2008. Methods in elastic tissue biology: Elastin isolation and purification. Methods 45:1, 32-41. [CrossRef]

9. Willeke F. Daamen, Suzan T.M. Nillesen, Ronnie G. Wismans, Dieter P. Reinhardt, Theo Hafmans, Jacques H. Veerkamp, Toin H. van Kuppevelt . 2008. A Biomaterial Composed of Collagen and Solubilized Elastin Enhances Angiogenesis and Elastic Fiber Formation Without Calcification. Tissue Engineering Part A 14:3, 349-360. [Abstract] [Full Text PDF] [Full Text PDF with Links]

10. Willeke F. Daamen, Suzan T.M. Nillesen, Ronnie G. Wismans, Dieter P. Reinhardt, Theo Hafmans, Jacques H. Veerkamp, Toin H. van Kuppevelt . A Biomaterial Composed of Collagen and Solubilized Elastin Enhances Angiogenesis and Elastic Fiber Formation Without Calcification. Tissue Engineering, ahead of print. [Abstract] [Full Text PDF] [Full Text PDF with Links]

11. W. F. Daamen, P. J. Geutjes, H. T. B. van Moerkerk, S. T. M. Nillesen, R. G. Wismans, T. Hafmans, L. P. W. J. van den Heuvel, A. M. A. Pistorius, J. H. Veerkamp, J. C. M. van Hest, T. H. van Kuppevelt. 2007. "Lyophilisomes": A New Type of (Bio)capsule. Advanced Materials 19:5, 673-677. [CrossRef]

12. Peter C. Johnson, Antonios G. Mikos Advances in Tissue Engineering, Volume 1: Angiogenesis . [Citation] [Full Text HTML] [Full Text PDF] [Full Text PDF with Links] 